\title{
Avaliação do desempenho docente: conflitos, incertezas e busca de sentido(s)
}

\section{Teacher performance evaluation: conflict, uncertainties and the search for meaning(s)}

\author{
Ana Maria Costa e Silva ${ }^{1}$ \\ Rosalinda Herdeiro ${ }^{1}$
}

\begin{abstract}
RESUMO
O texto que propomos parte de uma pesquisa longitudinal, realizada em Portugal entre 2008 e 2010, com professores do $1^{\circ}$ Ciclo do Ensino Básico. Procura evidenciar os conflitos e incertezas que a avaliação do desempenho docente tem produzido e a busca de sentido(s) para esta avaliação e para o 'ser professor/a'. A implementação de sistemas de avaliação do desempenho dos professores insere-se na procura de soluções para esta inquietação. Foi o que aconteceu em Portugal, em Janeiro de 2007, com a publicação em Diário da República do novo Estatuto da Carreira Docente e o Decreto que regulamentava a Avaliação do Desempenho Docente. As tensões emergiram entre docentes e Ministério da Educação, agudizaram-se com a tomada de consciência da problemática da avaliação do desempenho dos docentes com impacto na carreira profissional e provocaram incertezas e desmotivação face ao sentido do trabalho docente com impacto na identidade profissional dos professores.
\end{abstract}

Palavras-chave: avaliação; desempenho docente; identidade(s).

\begin{abstract}
This article stems from a longitudinal research carried out with primary school teachers in Portugal between 2008 and 2010. The research sought to identify the conflicts and uncertainties, which have been caused by the evaluation of teacher performance, as well as to search for meaning(s) related
\end{abstract}

DOI: $10.1590 / 0104-4060.41522$

1 Universidade do Minho. Instituto de Educação. Braga, Portugal. Campus de Gualtar, 4710-057.E-mails: anasilva@ie.uminho.pt; rosalinda.herdeiro@gmail.com 
to that evaluation and to 'being a teacher'. The implementation of systems for the evaluation of teacher performance fits into the search for solutions to that concern. This is what happened in Portugal, in January 2007, when the new Statute of the Teaching Profession and the law to regulate Teacher Performance Assessment were published in Diário da República - the official government publication. Tensions arose between teachers and the Ministry of Education and they were aggravated by an awareness of how the problem of teacher performance evaluation would impact on the professional career of teachers and how it would cause uncertainties and demotivation concerning the vocation of teaching and its subsequent impact on the professional identity of teachers.

Keywords: evaluation; teacher performance; identity(ies).

\section{Introdução}

A avaliação do desempenho docente em Portugal inscreve-se numa perspetiva mais ampla da avaliação, nomeadamente no âmbito das políticas públicas que se iniciam na década de 90 do século passado, como condição de progressão na carreira e de "garantia" da qualidade profissional e do "serviço público". No âmbito da Educação, este processo começa com a avaliação das escolas, com incidência nos resultados das aprendizagens dos seus estudantes, cujo objetivo era a melhoria do desempenho das escolas e dos seus principais intervenientes - os professores e os alunos.

A Estratégia de Lisboa (2000) define um plano de desenvolvimento estratégico, contendo orientações que realçam as questões da educação e formação num contexto de aprendizagem ao longo da vida, atribuindo uma acrescida relevância à educação e formação. A qualidade do ensino é uma das principais preocupações da política educacional, reconhecendo que um corpo docente bem formado e motivado é um elemento essencial, sendo, por isso, imprescindível continuar a melhorar as condições para o exercício atrativo da profissão docente. (PAPADOPOULOS, 2005).

Em 2007, em Portugal, o Conselho Nacional de Educação debatia a importância da qualidade na educação, centrando-se, também ele, na crescente exigência de uma economia que dependia do conhecimento e da qualidade da educação. O relatório Como vamos melhorar a Educação em Portugal (CONSELHO NACIONAL DE EDUCAÇÃO, 2007, p. 8-14) apresenta um conjunto de contributos para uma estratégia nacional de melhoria da educação, sustentando a importância do compromisso e da responsabilidade social. Apesar destes con- 
tributos, questionamos se eles foram atendidos pelas entidades governamentais quando reformularam e promulgaram dois dos principais diplomas que regem a vida profissional do professor: o Estatuto da Carreira Docente (ECD, Decreto-Lei $n^{0}$ 15/2007, de 19 de janeiro) e a Avaliação de Desempenho Docente. (ADD, Decreto Regulamentar $\mathrm{n}^{\circ}$ 2/2008, de 10 de janeiro).

A pesquisa que realizamos emerge precisamente de uma curiosidade e interrogação sobre o impacto de algumas das decisões político-educacionais. Trata-se de uma pesquisa longitudinal, com professores do $1^{\circ}$ Ciclo do Ensino Básico, tendo como objetivo central perceber as consequências do ECD e da ADD, na(s) identidade(s), na carreira e no desenvolvimento profissional dos docentes.

Neste texto salientam-se algumas tendências das políticas educacionais atuais e, sobretudo, os seus efeitos nos contextos de trabalho, o que nos poderá ajudar a compreender as atitudes dos professores face à exigência de promover aprendizagens de qualidade nos alunos.

\section{A avaliação do desempenho docente em Portugal: pressupostos e experiências}

\section{Contextualização da avaliação do desempenho a partir do novo ECD}

Desde a definição das linhas orientadoras contidas no documento Estratégia de Lisboa (2000), e a partir dos pressupostos definidos nesse documento, o Jornal Oficial da União Europeia tem publicado relatórios de avaliação intercalar (2004, 2006 e 2008), dando conta dos progressos realizados e das dificuldades persistentes no espaço europeu e apelando à adoção de reformas urgentes na educação para garantir um contributo mais eficaz para a concretização de um ensino de qualidade para todos.

Como resposta às preocupações educativas e formativas existentes, o governo português promove um conjunto de medidas que visam concretizar mudanças estruturais de modo a obter-se maior sucesso escolar. É neste contexto que o Estatuto da Carreira Docente (ECD) do Ensino Básico e a Avaliação de Desempenho Docente (ADD) são reformulados no sentido de fomentar a mudança educativa, elegendo a qualidade do desempenho dos docentes como uma condição fundamental para o sucesso educativo e, simultaneamente, para o desenvolvimento profissional do professor.

No preâmbulo do ECD (Decreto-Lei no 15/2007) assume-se como imperativo político a necessidade de alteração do Estatuto da Carreira Docente, 
considerando-se que o trabalho organizado dos docentes é fundamental na promoção do sucesso educativo, na prevenção do abandono escolar e na melhoria da qualidade do ensino. Também se assume que é indispensável estabelecer um regime de avaliação de desempenho mais exigente e com efeitos no desenvolvimento da carreira que permita identificar, promover e premiar o mérito e valorizar a atividade letiva. Relativamente à avaliação dos professores, o ECD assume como objetivos gerais melhorar os resultados escolares dos alunos e da qualidade das aprendizagens e proporcionar orientações para o desenvolvimento profissional e pessoal dos professores através do reconhecimento do mérito e da excelência.

Na opinião de Lima (2011), a contextura processual deste modelo "transpira" hiperburocracia e competitividade porque recorre à utilização de um conjunto demasiado excessivo de instrumentos de registo normalizados. Sanches (2008, p. 178) acrescenta que a avaliação é orientada para a prestação de contas, pois "[...] a preocupação excessiva em quantificar o mérito profissional, através do preenchimento de grelhas complexas carregadas de números e fórmulas de modo a controlar a progressão profissional dos professores" dificulta qualquer articulação possível entre a avaliação do desempenho e o desenvolvimento profissional.

Foi na convergência das medidas políticas e da literatura mais recente sobre avaliação do desempenho com a nossa experiência profissional que se tornou relevante identificar, junto aos professores participantes, os constrangimentos e conflitos, expressos ou implícitos, que poderiam estar na origem da desmotivação profissional que emergia e perceber os sentidos atribuídos por eles ao cumprimento legal da avaliação do (seu) desempenho.

\section{Ser professor/a e a avaliação do desempenho}

Apesar do consenso social de que as escolas e os professores vivem tempos de mudança, que sentido segue essa mudança? Que implicações têm nas instituições educativas e no trabalho dos seus atores centrais estas mudanças e a avaliação do seu desempenho profissional?

A educação exige, como é referido nos diferentes normativos já enunciados, um trabalho docente altamente qualificado, adquirido em moldes diferentes dos conseguidos até hoje (DEAN, 1991), centrado, essencialmente, no desenvolvimento profissional docente com "[...] ênfase na colaboração, cooperação entre os professores e outros responsáveis legais da educação" (DAY; SACHS, 
2004, p. 7), sem que os professores abdiquem do estatuto de "guardiões da sua profissionalidade". (SILVA, 2007, p. 162).

Evidenciando essa perspetiva, de valorização da profissão docente, a intervenção de Canário (2007), na conferência promovida pela Presidência Portuguesa do Conselho da União Europeia, foi explícita no sentido de confiar que os objetivos centrais traçados teriam a sua consecução plena se os professores fossem motivados profissionalmente para a sua prática docente. Neste contexto de mudança serão os professores europeus, e particularmente os portugueses, motivados para os objetivos que as reformas recentes preconizam?

Day e Sachs (2004, p. 5) referem "[...] que há evidências de que o professor está a ser desqualificado e o seu trabalho intensificado". Os professores sentem que os decisores políticos lhes impõem cada vez mais as mudanças, através de documentos legislativos, retirando-lhes autonomia e acrescendo-lhes responsabilidades. Por isso, os autores referem que o currículo nacional imposto, a inclusão de processos de gestão, monitorização e de avaliação nos sistemas educativos coincidem, frequentemente, com períodos de desestabilização, aumento de trabalho esperado, intensificação do trabalho do professor e uma crise na identidade profissional. Esta crise de identidade advém do sentimento de perda da confiança pública depositada na capacidade do professor em desenvolver um bom trabalho na escola.

A componente afetiva do/no trabalho, como salienta Silva (2007, p. 159), "[...] é um fator importante que interfere nas ações e emoções dos profissionais com incidência no seu desempenho e, sobretudo, na sua realização profissional". Para Lopes e Pereira (2008, p. 97), "[...] a identidade, pelo menos enquanto sentimento é em si uma relação coerente entre o eu e o mundo (os outros, o grupo)".

Para melhorar o desempenho dos professores, o seu desenvolvimento deve ser definido dentro dos contextos das suas necessidades pessoais e institucionais de modo a favorecer o seu "comprometimento e disposição em relação à aprendizagem", enquanto aprendente ao longo da vida. (DAY, 2004, p. 186).

Em Portugal, o estudo desenvolvido por Flores, Day e Viana (2007) pretendeu analisar e compreender a(s) forma(s) como os professores (portugueses e ingleses) entendem as mais recentes mudanças (curriculares) ocorridas no ensino, bem como os seus efeitos no modo como encaram o profissionalismo docente e a(s) sua(s) identidade(s) profissional(ais). O estudo relata que, em 2004, os professores portugueses sentiam-se satisfeitos e empenhados na sua tarefa educativa. Em contrapartida, os professores ingleses, devido às reformas impostas, afirmavam-se insatisfeitos e, quando questionados sobre as condições de trabalho, o pessimismo é ainda mais significativo: o aumento de volume do trabalho após o horário letivo, o reconhecimento do aumento da burocracia e que as inovações impostas contribuíram para desmotivação profissional com 
impacto na identidade. Após três anos da implementação deste estudo (em 2007), os professores portugueses conheceram, da equipa ministerial responsável pela educação, a reformulação do Estatuto da Carreira Docente (ECD) do Ensino Básico e a regulamentação da Avaliação de Desempenho Docente (ADD). Será que os professores portugueses continuam satisfeitos e empenhados no seu trabalho diário? Terão, de facto, os referidos documentos legislativos impulsionando o desenvolvimento profissional e a qualidade do trabalho docente?

\section{Objetivos da pesquisa e metodologia}

Tomando como referência a contextualização feita anteriormente, a pesquisa realizada teve como principal finalidade identificar os elementos intervenientes no desenvolvimento profissional dos professores em articulação com a carreira docente e as identidades profissionais. Para tal, definimos dois objetivos gerais: i) identificar as percepções que os professores do $1^{\circ}$ Ciclo do Ensino Básico (CEB) têm dos documentos legislativos emanados recentemente; ii) compreender as implicações desta mudança educativa na (re)construção da(s) identidade(s) profissional(ais). Definimos, também, os seguintes objetivos específicos: i) conhecer o impacto dos normativos em estudo no desenvolvimento profissional dos professores e na carreira docente; ii) analisar o impacto da legislação referida nas práticas pedagógicas dos professores e na escola/agrupamento; iii) conhecer as suas percepções de progressão na carreira; iv) perceber a relação entre progressão na carreira e desenvolvimento profissional.

Tendo em atenção os objetivos propostos para esta pesquisa, optamos por combinar as abordagens quantitativas e qualitativas. A abordagem qualitativa foi privilegiada através da utilização de narrativas biográficas escritas, focus group e pesquisa documental. A abordagem quantitativa foi explorada nas respostas a um questionário, composto por questões fechadas, questões abertas e escalas tipo Likert, distribuído a 396 professores do $1^{\circ} \mathrm{CEB}$. A percentagem de retorno do questionário foi de $63 \%$, correspondendo a 249 questionários do total dos distribuídos que, posteriormente, foram tratados e analisados no programa SPSS (Statistical Package for the Social Sciences), versão 17.0.

Neste texto iremos evidenciar apenas alguns dos resultados decorrentes, tanto do estudo qualitativo e da análise de conteúdo através do Programa NVivo 9.0, como da aplicação do questionário e da análise estatística efetuada com os testes Chi-Square e T-Test. 


\section{Entre o prescrito e o real: uma trajetória imprevista}

\section{Decisões e experiências: vozes dissonantes}

Existem diferentes modelos de avaliação aos quais vários autores se referem (SIMÕES, 2000; SANCHES, 2008; FERNANDES, 2008): centrados no perfil do professor, nos comportamentos do docente na sala de aula, nos resultados escolares e na prática reflexiva. Esta diversidade de modelos influencia a preparação de um processo de avaliação de docentes com a intenção de promover o desenvolvimento profissional.

Na opinião de Sanches (2008, p. 134), o novo ECD propõe um processo de avaliação de desempenho que articula características dos diferentes modelos, embora reconheça alguma predominância do modelo centrado no perfil do professor, pelo facto de o mesmo processo ocorrer "[...] de acordo com o grau de concordância aferido em relação a traços ou características de um perfil previamente fixado", podendo comprometer todo o processo. Assim, no Decreto-Lei $n^{\circ}$ 240/2001 são definidos os perfis de competência do professor exigidos para o desempenho de funções docentes incidindo nas dimensões profissionais e éticas, de desenvolvimento do ensino e da aprendizagem, de participação na escola e de relação com a comunidade e de desenvolvimento profissional ao longo da vida, referidos no primeiro decreto que regulamentava o processo de avaliação dos professores.

Em 2007, com a publicação do novo ECD, para cada uma das dimensões antes referidas são identificados diversos parâmetros (por exemplo: na dimensão "profissional e ética" são considerados o nível de assiduidade e o serviço distribuído; na dimensão do "desenvolvimento e formação ao longo da vida" apenas se consideram as ações de formação contínua frequentadas pelos professores).

Das constantes reivindicações efetuadas pelas entidades sindicais e pelos professores, ao Ministério da Educação, foram assumidas algumas alterações ao ECD publicado em 2007 e ao ADD, publicado em 2008, de modo que a essência dos documentos se aproximasse dos interesses e das necessidades dos profissionais do ensino.

Independentemente da opinião dos responsáveis políticos sobre as revisões e reformulações do ECD e do modelo de ADD, realizadas ao longo da primeira década do século XXI, elas continuam a ter uma aceitação controversa nas escolas, sendo assumidas pelos professores como instrumentos de desvalorização do seu trabalho e como um entrave ao sucesso educativo dos alunos.

Para alguns autores (FERNANDES, 2008; BARREIRA; REBELO, 2008), a adoção de um modelo avaliativo baseado no desempenho docente 
sugere oportunidades de desenvolvimento profissional e contribui " [...] significativamente para melhorar a vida pedagógica das escolas e a qualidade de serviço que prestam à sociedade em que se inserem". (FERNANDES, 2008, p. 29). Contudo, é importante conhecer se as escolas possuem oportunidades de desenvolvimento para oferecer aos professores, em igualdade de circunstâncias, e se elas estimulam a motivação e o empenho no trabalho docente de modo a concretizar a qualidade pedagógica nas escolas.

As medidas adotadas pelos sucessivos governos, "[...] saltando de reformas em reformas à procura de soluções $[. .$.$] movidos pela eventual convicção de que$ é possível resolver por decreto lei os problemas com que o sistema educativo se confronta", não resultam em soluções, porque as escolas carecem de respostas múltiplas que ultrapassam, em muito, a produção legislativa ou a capacidade individual de mudança, necessitando de um corpo docente totalmente motivado e envolvido num processo reflexivo e colaborativo. (TEIXEIRA, 2001, p. 194).

Os professores participantes na pesquisa que realizamos dão conta de uma situação real de mal-estar docente (ESTEVE, 1992), uma "vaga de desencanto" (BOLÍVAR, 2007, p. 16), colocando, deste modo, em questão os resultados conseguidos com as reformas top-down, pelo facto de as vozes dos professores libertarem reações desajustadas à mudança, contrariando, objetivamente, as interpretações das necessidades dos governos portugueses para melhorar o sistema educativo.

Contudo, no início da década anterior - antes da publicação da recente legislação - os professores participantes nesta mesma pesquisa davam conta de mundos socioprofissionais que incidiam essencialmente sobre o modo de estar/ ser do docente na profissão e de se desenvolver profissionalmente, exteriorizando motivação e satisfação em ser um professor (diferente) na escola e na sociedade de hoje. (HERDEIRO, 2010). Nas palavras de uma das participantes neste estudo "todos nós sentíamos a escola como nossa". (Carolina, narrativa oral, 2007).

Podemos, assim, verificar como, no momento anterior à publicação dos normativos a que nos vimos referindo, os professores manifestavam atitudes reflexivas, acreditando que trabalhar em conjunto era possível e que trazia benefícios para a escola.

A nova versão do ECD, publicada em Janeiro de 2007, veio introduzir diversas mudanças no modo de pensar e exercer a profissão docente. Segundo Sanches (2008, p. 11), emergiu "num contexto de contra-ciclo social e organizacional", comprometendo o processo de mudança. Ou seja, o documento surgiu numa altura de grande complexidade do trabalho docente, devido, essencialmente, ao alargamento das suas funções, aos comportamentos problemáticos dos alunos e à dificuldade de ser professor na escola e na sociedade de hoje.

Assim, a regulamentação da atividade docente em moldes mais rígidos e restritivos encontrou na classe docente uma rejeição generalizada da aceita- 
ção de tais mudanças, assumindo emoções e atitudes de angústia e incerteza, de revolta, de ansiedade, de injustiça e de desânimo profissional. Conforme expressa Diogo, "criando momentos controversos nas escolas e nas relações profissionais". (Diogo, narrativa escrita, 2008).

De acordo com Lima (1998), oferecer resistência é uma das possibilidades de contrariar certas orientações políticas, principalmente através da ação coletiva, social e organizacional dos professores. Segundo este autor, "[...] resistir às políticas não é uma coisa boa nem má - tudo depende das políticas". (LIMA, 1998, p. 23). Deste ponto de vista, quando as políticas são nefastas e injustas, evidentemente que o ato de resistência é fundamental.

As atitudes de mal-estar docente traduzem uma evidente crise de identidade e o enfrentamento desta crise conduz a diferentes tipos de reações.

De angústia e incerteza: devido à intensificação das exigências em relação às tarefas a desenvolver na escola. De revolta: porque o professor sente a sua imagem social/profissional cada vez mais degradada na sociedade, expressando-se deste modo:

[...] não é possivel trabalhar com gosto, dá vontade de desistir, sinto que estamos a ser esquecidos e desrespeitados por todos [...] portugueses, motivados para os objetivos que as reformas recentes preconizam? (Elsa, narrativa escrita, 2008).

[...] incompreendidos pela sociedade em geral [...] e cansados [...] (Sónia, narrativa escrita, 2008).

Day e Sachs (2004, p. 5) referem “[...] que há evidências de que o professor está a ser desqualificado e o seu trabalho intensificado". Os professores sentem que os decisores políticos lhes impõem cada vez mais as mudanças, através de documentos legislativos, retirando-lhes autonomia e acrescendo-lhes responsabilidades. Por isso, os autores referem que o currículo nacional imposto, a inclusão de processos de gestão, monitorização e de avaliação nos sistemas educativos coincidem, frequentemente, com períodos de desestabilização, aumento de trabalho esperado, intensificação do trabalho do professor e uma crise na identidade profissional. Esta crise de identidade advém do sentimento de perda da confiança pública depositada na capacidade do professor em desenvolver um bom trabalho na escola.

A componente afetiva do/no trabalho, como salienta Silva (2007, p. 159), "[...] é um fator importante que interfere nas ações e emoções dos profissionais 
com incidência no seu desempenho e, sobretudo, na sua realização profissional”. Para Lopes e Pereira (2008, p. 97), "[...] a identidade, pelo menos enquanto sentimento é em si uma relação coerente entre o eu e o mundo (os outros, o grupo)". Para melhorar o desempenho dos professores, o seu desenvolvimento deve ser definido dentro dos contextos das suas necessidades pessoais e institucionais de modo a favorecer o seu "comprometimento e disposição em relação à aprendizagem", enquanto aprendente ao longo da vida. (DAY, 2004, p. 186).

De ansiedade: porque se verifica uma grande vulnerabilidade da escola face aos problemas sociais, sentida mais do que ninguém por parte dos professores, como afirma uma professora respondente: "sinto-me mais ansiosa e preocupada". (Q. 80). No seu trabalho diário os professores são hiper-responsabilizados por tarefas e funções que muitas vezes transcendem o âmbito das suas competências, tal como subscreve esta professora: "a minha tarefa como professora pode ficar abalada, são tantas as solicitações...”. (Elsa, narrativa escrita, 2008).

De injustiça: como refere um professor respondente ao questionário: "porque atualmente a forma de avaliação de desempenho é injusta: cria desigualdades e provoca situações de injustiça". (Q. 141).

Leyens e Yzerbyt (1999, p. 285) afirmam que "[...] as interações implicam partilha de bens materiais e simbólicos". A percepção de injustiça ao nível dessa partilha contribui muitas vezes para os conflitos entre grupos, colaborando para a discriminação e os preconceitos, como expressa Sónia: "a longo prazo causará inveja, discriminação, 'namoros', rivalidades e segredinhos”. (Sónia, narrativa escrita, 2008).

A análise das reações dos professores evidencia o mal-estar docente nas escolas, emergente das reformas educativas. Esta situação tem, naturalmente, consequências na vida dos professores, principalmente no modo de se desenvolverem, implicando uma procura de estratégias que se adequem ao momento e à etapa da carreira em que se encontram.

\section{Conflitos, incertezas e (des)motivações}

Com a publicação do novo ECD e do modelo de ADD emergiram reações negativas nos professores, como já fomos evidenciando com alguns resultados da nossa pesquisa, induzindo a situações de conflito entre a classe docente como, por exemplo, refere esta professora: "Claro que toda esta situação foi provocada pela recente publicação dos documentos legislativos, em nome da mudança educativa necessária que não agradou aos professores [...]". (Amélia, narrativa escrita, 2008). Na escola, como em qualquer outra instituição, as 
relações entre as pessoas são um fenómeno que caracteriza o contexto social em que se desenvolve o ofício. Ou seja, as relações (inter)pessoais assumem relevância nas sociedades que aprendem e que se desenvolvem, porque interferem nos modelos de aprendizagem e nos percursos de formação das pessoas. (TAVARES, 1993, 1996; SECO, 2002).

Apesar do apreço dispensado às relações (inter)pessoais num contexto de mudança educativa, os professores participantes na nossa pesquisa estão reticentes quanto ao efeito positivo que a ADD possa produzir no crescimento das pessoas, pelo facto de despoletar más relações profissionais. Neste sentido, salientamos a afirmação do professor Diogo: "[...] originando más relações laborais [...] fizeram perigar as relações profissionais dentro das escolas [...] incentivou a separação profissional e trouxe, logicamente, o deteriorar das relações profissionais". (Diogo, narrativa escrita, 2008). Face a esta situação desconfortável na escola, os professores revelam comportamentos desmotivadores, investindo menos nas relações (inter)pessoais e evitando a convivência social devido à ausência de confiança e apoio profissionais.

Com efeito, no contexto educativo, as atitudes são moldadas na interação do professor com o ambiente em que trabalha. Quando o contexto de trabalho sofre alterações substanciais pode provocar atitudes favoráveis ou desfavoráveis, conforme a satisfação ou não das necessidades profissionais.

$\mathrm{Na}$ opinião de cerca de metade dos professores da nossa amostra, a avaliação parece não interferir na sua atitude profissional na escola $(53,8)$, mas para cerca de $42 \%$ dos professores ela influencia negativamente as suas atitudes na escola devido, sobretudo, à amplitude que as exigências "extras" assumem na profissão docente em detrimento do processo de ensino e aprendizagem.

\section{QUADRO 1 - A INFLUÊNCIA DA AVALIAÇÃO DOCENTE NA(S) ATITUDE(S) DOS PROFESSORES COM EFEITOS NA IDENTIDADE PROFIS- SIONAL}

\begin{tabular}{|l|c|c|c|c|}
\hline Indicadores & Positivo & Neutro & Negativo & Q.Q \\
\hline $\begin{array}{l}\text { De que forma a avaliação do desempenho } \\
\text { docente influencia a sua atitude profissional } \\
\text { na escola? }\end{array}$ & 4,5 & 53,8 & 41,7 & $98,2 * * *$ \\
\hline
\end{tabular}

Nota*** $\mathrm{p}<0,001$

FONTE: As autoras (2015).

Emerge, assim, um conjunto de aspetos que modelam as atitudes dos profissionais - o desleixo, a desconfiança, o alheamento, a desistência - tal como nos indicam as respostas dos profissionais às perguntas abertas do questionário: 
A preocupação com a avaliação do desempenho potencia o desleixo pelo trabalho com os alunos, cria falta de tempo para preparar, refletir, planificar. (Q.7). Nestes moldes é uma má influência porque desconfiamos de tudo e de todos. É muito constrangedor. (Q. 29). As leis que estão neste momento em vigor, relativamente à educação fazem-me perder a confiança num futuro melhor. (Q.49). Sinto vontade de abandonar a profissão. Não vale a pena continuar a lutar. (Q. 75). Nunca houve motivos maiores para tanta desconfiança [...] antes se conversava, confiava-se... ria-se, jantava-se ... isto actualmente parece esquecido! (Amélia, narrativa oral, 2008). Com este tipo de avaliação a relação profissional... Está mal, para falar exacto, está péssima [...]. (Manuel, GD3). [...] então nós temos que nos desviar e não podemos colaborar, porque as pessoas criam barreiras [...]. (Carolina, narrativa oral, 2010).

No sentido de evitar este tipo de situações conflituosas ou, no mínimo de desconfiança, Rogers (1985) defende que as relações deverão ser abertas, verdadeiras, autênticas e empáticas, emergindo "uma rede de laços" que "unem os vários atores ou grupos de atores no mundo social". (LIMA, 2002, p. 73).

Os professores não reconhecem ou, no nosso caso, deixaram de reconhecer nos colegas as figuras de confiança com quem podem partilhar as preocupações e os saberes profissionais e pessoais: uns não estão interessados no trabalho dos colegas; outros desejam apropriar-se do trabalho dos colegas e afirmar que é de sua autoria e temos ainda aqueles que revelam "inveja" no empenho e no trabalho desenvolvido pelos colegas. Face a esta falta de confiança crescente, os professores elegem os colegas considerados "bons amigos" como as figuras ideais para partilhar e refletir na prática docente, porque os bons amigos acreditam e participam numa relação aberta e de apoio mútuo, com resultados no desenvolvimento de todos.

Apesar da possibilidade de algum exagero emocional poder emergir por parte dos professores face à situação complexa em que se vêem envolvidos, também é verdade que algo de muito forte os afetou e perturbou, o que justifica o (re) nascer de situações complexas entre os professores que pareciam ultrapassadas.

Por isso, é importante que se reflita por que é que a desconfiança, a ansiedade, a desmotivação, entre outros elementos descompensadores para o investimento exigido por parte dos professores, persistem nas escolas. 


\section{A busca de sentido(s) na avaliação e a (re)construção da identidade profissional}

Conforme já salientamos nos pontos anteriores, as políticas educativas atuais e os normativos nos quais centramos a nossa pesquisa evidenciam determinadas exigências ao sistema educativo em geral e aos docentes em particular, que implicam: i) formação permanente; ii) atenção redobrada à diversidade sociocultural dos alunos; iii) trabalho colaborativo; e iv) disponibilidade para uma diversidade de relações profissionais requeridas, desde os pais e encarregados de educação até aos autarcas e aos empresários.

Recentemente, a avaliação do desempenho docente constitui a dimensão profissional mais exigente, complexa e a mais contestada pelos docentes no quotidiano escolar. A avaliação deverá assentar em princípios básicos de rigor, de transparência, de exigência e de objetividade, tendo em vista promover o desenvolvimento profissional dos professores, reconhecendo e valorizando o esforço, o mérito e a excelência profissionais. Para além da obediência a estes princípios, a avaliação tem de ser perspectivada de um modo integrado e contextualizado, ligada à avaliação das escolas onde os docentes exercem a sua atividade e tendo sempre como referência um perfil profissional, prévio e claramente definido, adequado ao contexto em que se encontra a exercer funções.

Porém, nesse ciclo de cuidados também será importante destacar os modos como as decisões político-educativas são introduzidas nos contextos escolares que de certa forma regulam as experiências e os sentires dos profissionais.

$\mathrm{Na}$ opinião de alguns autores, como Aguiar e Alves (2010), De Ketele (2010) e Ferro (2011), qualquer modelo de avaliação enfrenta, no terreno, a sua maior contrariedade. Relativamente a esta perspetiva, pensamos que ela reflete bem o que encontramos nos resultados da nossa pesquisa, essencialmente quando percebemos que há uma frágil e nebulosa percepção dos conceitos e práticas inerentes à avaliação do desempenho. Contudo, atendendo às percepções e às experiências dos professores que participaram neste estudo, percebemos que se trata de uma situação que vai para além da (in)compreensão de conceitos, de contrariedades profissionais, de sentimentos momentâneos e de lutas sindicais, pelo facto de se sentir que as estruturas que enriqueciam as relações pessoais, profissionais e sociais sofreram abalos consideráveis.

Em 2006, antes da publicação dos documentos legislativos, os professores, através das vozes dos Sindicatos, percepcionaram "as novidades" políticas educacionais do governo como "instrumentos" de auxílio na promoção de algumas estruturas e nos processos do sistema educativo menos cimentados nas escolas - a promoção de culturas colaborativas e a criação de um novo modelo de for- 
mação contínua no contexto escolar - edificando um sentimento de esperança na mudança da escola. Com isto não pretendemos dizer que os professores se sentiam otimistas no futuro, antes pretendiam vincular-se ao propósito de serem julgados como (novos) "agentes da esperança" na educação, porque estavam confiantes e dispostos a lutar por uma escola melhor, como nos revela a Sónia na sua narrativa escrita em 2008:

A palavra que frequentemente me surge quando releio o novo Estatuto da Carreira Docente (ECD) e o diploma da avaliação, é ESPERANÇA. Tenho uma profunda esperança de que as teorias que iluminaram os autores destas mudanças caiam por terra com o decorrer da execução de todas estas alterações e possamos de alguma forma encontrar um novo caminho que torne a escola um lugar aprazivel para todos. (Sónia, narrativa escrita, 2008).

Day (2004) defende que a esperança é o fundamento do ensino apaixonado e, por isso, em momentos difíceis, ter esperança significa que um indivíduo não irá ceder perante a ansiedade opressiva. Porém, depressa os professores se aperceberam que mais uma vez a esperança na mudança da escola "caía por terra", porque o ímpeto de mudança política não se traduzia em melhorias significativas do sistema educativo. Ou seja, enveredava-se por um caminho que progredia no sentido de empobrecer cada vez mais os contextos educativos, principalmente no domínio das (inter)relações profissionais, emergindo (novos) sentires indenitários, como é evidenciado nas palavras dos professores dentre as quais anteriormente citamos algumas.

Os sociólogos advertem que, na época em que vivemos a socialização já não é feita através da ideologia, mas através do sentir - época a que Perniola (1993) chamou de sensológica - privilegiando, deste modo, os sentidos que são produzidos e reproduzidos em redes interativas.

Na mesma obra, Perniola (1993, p. 50) defende que a nossa época, caracterizada essencialmente pela burocracia, rege-se por uma completa separação entre o agir e o sentir. Ou seja, de um lado está " [...] a organização que administra racionalmente as necessidades e dirige a realização dos objetivos, do outro está uma interioridade pulsional, um modo de ser sensível, emocional, afetivo que se opõe ao universo burocrático" e que assume uma posição cada vez mais forte e significativa na época em que vivemos. A partir do pensamento sociológico e nas experiências profissionais dos docentes, questionamos: como é o sentir (dos professores) numa situação em que o estatuto da carreira docente e a avaliação do desempenho detêm o monopólio do trabalho docente? 
Dessa "viagem" pelo mundo do sentir dos professores, conseguimos identificar três modos de sentir: a "desilusão", a "solidão" e a "ambição" profissionais, conforme sintetizamos na Figura 1.

Os modos de sentir identificados traduzem o(s) resultado(s) da vivência de experiências dos docentes nas dimensões abordadas - no desenvolvimento profissional, no desempenho docente e na progressão na carreira - assumindo um lugar pertinente e (in)questionável na compreensão da (re)construção da identidade profissional nos tempos atuais.

\section{FIGURA 1 - OS MODOS DE SENTIR DOS PROFESSORES COM CONSEQUÊNCIAS NA IDENTIDADE PROFISSIONAL}

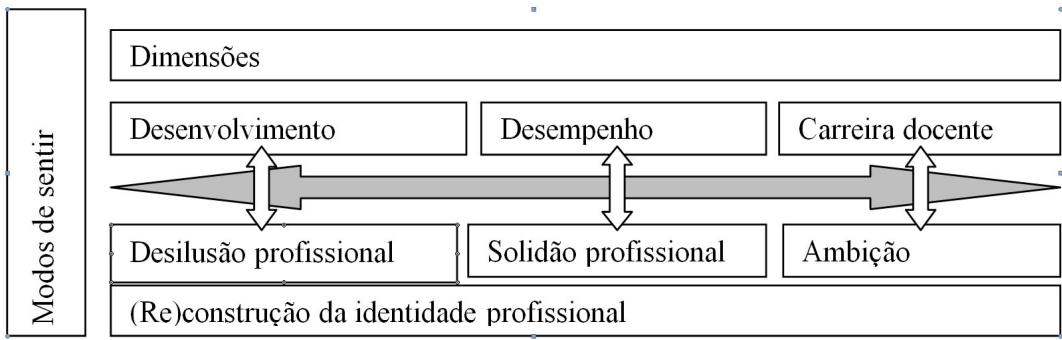

FONTE: HERDEIRO (2012, p. 295).

Assim, em nome de um novo profissionalismo, os professores vêem na contingência de ter de transformar os seus papéis profissionais e de se adaptarem a novos contextos de trabalho. Day e Gu (2010) dão conta de uma estrutura educacional problemática, procedente da necessidade dos professores exercerem outras funções para além daquelas que eles entendem ser da sua responsabilidade como profissionais do ensino, emergindo, deste modo, novos contextos de ensino e novas vidas profissionais.

$\mathrm{Na}$ perspectiva de um ensino de qualidade, os autores supracitados afirmam ser importante advertir os decisores políticos, internos e externos à escola, da necessidade de atender a determinados elementos considerados centrais na motivação e no (bom) desempenho dos professores: o compromisso no trabalho docente; as condições físicas e sociais do trabalho dos professores; a influência de acontecimentos na vida dos professores e das relações profissionais e organizacionais. (DAY; GU, 2010).

Os professores participantes neste estudo denunciam desmotivação e desilusão no que se refere à promoção do desenvolvimento profissional na escola, tanto no âmbito individual como no coletivo. Por sua vez, esse sentimento de desilusão leva a que o desempenho do professor possa ser questionado por 
ele próprio por ser sustentado num trabalho gradualmente solitário marcado, essencialmente, pela ausência de apoio, de partilha de experiências significativas e de um trabalho em equipa.

Todavia, como contraponto a essa situação complexa e desmotivadora, os docentes revelam outro modo de sentir que de certa forma tenta compensar a desilusão e a solidão profissionais experienciadas - a ambição de progredir na carreira - desviando as atenções do professor do desenvolvimento de uma prática pedagógica sustentável para o desejo desenfreado de progredir na carreira. Isto é, o professor deseja chegar ao topo da carreira e de preferência o mais rápido possível para poder aceder a escalões com melhor remuneração, superando o desejo de "aprender mais" para ser melhor professor.

Dessa maneira, esses modos de sentir dos professores denunciam a fabricação de (novas) vidas profissionais que condicionam a profissão Ser professor: embora abraçada com gosto desde o início, os professores sentem que é difícil continuar a investir e dedicar-se profissionalmente num ambiente onde "ser melhor que o outro" prevalece às boas relações pessoais e profissionais.

Portanto, essa dificuldade de continuar a investir advém particularmente: i) do trabalho solitário que o professor desenvolve diariamente sem contar com o reconhecimento, o apoio e a colaboração dos pares e da liderança; ii) da sobrevalorização da carreira em detrimento do desenvolvimento profissional, constituindo a chegada ao topo uma ambição premeditada e, de certo modo, desmedida e finalmente, iii) o desencanto pela profissão, forçada pelas exigências impostas pelas diretrizes políticas.

Nessa perspectiva, os professores refletem a desagregação que está a acontecer entre a carreira docente e o desenvolvimento profissional, colocando em questão a dimensão sinonímica investigada e interpretada pelos especialistas da educação. Por outras palavras, os docentes, ao investirem na carreira docente, poderão não estar a pensar diretamente na (sua) aprendizagem e no (seu) desenvolvimento profissional com a intencionalidade de "aprender para ser melhor professor", mas com o fim de conseguir "um lugar considerável" na carreira que lhe permita usufruir de (alguma) estabilidade profissional e económica.

Relativamente à avaliação docente, Correia e Matos (2001) advogam que face às potencialidades formativas e reguladoras que lhe são atribuídas, a avaliação parece ter adquirido uma tal centralidade na vida das escolas que tende a transformar-se no núcleo estruturante da definição do ofício do professor. $\mathrm{Ou}$ seja, na sequência das diretrizes políticas europeias sustentadas na urgência de um ensino de qualidade, Ser professor passou a estar "intimamente" ligado ao ato de ser avaliado, assumindo tal importância que a avaliação se sobrevalorizou a outras estruturas que caracterizam a profissão docente, como as componentes pedagógica e relacional. 
Na pesquisa que realizamos, foi perceptível que a avaliação do desempenho docente nos remete para a presença de contextos educativos dominados essencialmente pelo individualismo e pela competição profissionais, interferindo no desenvolvimento e na identidade do professor.

Segundo Teodoro (2006), essas dificuldades e preocupações estimuladas pela epidemia política que atinge a generalidade dos países durante a última década não são apenas instrumentos de mudança do sistema educativo e das escolas, mas são também, na opinião de Ball (2002), poderosos meios para mudar o sentido do que é ser professor.

Grosso modo é admitir que emergem novos modos de fabricação da alma dos professores (FOUCAULT, 1997), com incidência na sua identidade profissional.

\section{REFERÊNCIAS}

AGUIAR, J. L.; ALVES, P. A. A avaliação do desempenho docente: tensões e desafios na escola e nos professores. In: ALVES, M. P.; FLORES, M. A. (Orgs.). Trabalho Docente, Formação e Avaliação. Clarificar conceitos, fundamentar práticas. Mangualde: Edições Pedago, 2010. p. 229-258.

BALL, S. Reformar escolas/reformar professores e os terrores da performatividade. Revista Portuguesa de Educação, v. 15, n. 2, p. 03-23, 2002.

BARREIRA, C.; REBELO, P. V. Avaliação dos professores, desenvolvimento profissional e sucesso escolar dos alunos: uma conciliação possível? In: COLÓQUIO LUSO-BRASILEIRO SOBRE QUESTÕES CURRICULARES, IV.; COLÓQUIO SOBRE QUESTÕES CURRICULARES, VIII., 2008, Florianópolis, SC. Anais... Florianópolis, SC: Universidade de Santa Catarina, 2008.

BOLÍVAR, A. Um olhar atual sobre a mudança educativa: onde situar os esforços de melhoria? In: LEITE, C.; LOPES, A. (Org.). Escola, Currículo e Formação de Identidades. Porto: Edições Asa, 2007. p. 13-50.

CANÁRIO, R. Formação e desenvolvimento profissional dos professores. In: PRESIDÊNCIA PORTUGUESA DO CONSELHO DA UNIÃO EUROPEIA. Conferência Desenvolvimento profissional de professores para a qualidade e para a equidade da Aprendizagem ao longo da Vida. Lisboa, 2007.

CONSELHO NACIONAL DE EDUCAÇÃO. Como vamos melhorar a Educação em Portugal. Novos compromissos sociais pela Educação. Lisboa: CNE, 2007.

CORREIA, J. A.; MATOS, M. Solidões e Solidariedades nos quotidianos dos Professores. Porto: Edições Asa, 2001. 
DAY, C. A Paixão pelo Ensino. Porto: Porto Editora, 2004.

DAY, C.; GU, Q. The new lives of teachers. London: Routledge, 2010.

DAY, C.; SACHS, J. Professionalism, performativity and empowerment: discourses in the politics and purposes of continuing professional development. In: DAY, C.; SACHS, J. (Orgs.). International Handbook on the Continuing of Teachers. Maidenhead: Birks, Open University Press, 2004. p. 3-32.

DEAN, J. Professional Development in School. Milton Keynes: Open University Press, 1991.

DE KETELE, J. A avaliação do desenvolvimento profissional dos professores: postura de controlo ou postura de reconhecimento? In: ALVES, M. P.; MACHADO, E. A. (Org.). $O$ Pólo de Excelência. Caminhos para a Avaliação do Desempenho Docente. Porto: Areal Editores, 2010. p. 13-31.

ESTEVE, J. M. O mal-estar docente. Lisboa: Escher, 1992.

FERNANDES, D. Avaliação do desempenho docente: desafios, problemas e oportunidades. Lisboa: Texto Editora, 2008.

FERRO, E. O desenvolvimento e a avaliação de competência(s) no contexto da observação de aulas. In: MACHADO, E. A.; ALVES, M. P.; GONÇALVES, F. R. (Orgs.). Observar e Avaliar as Práticas Docentes. Santo Tirso: De Facto Editores, 2011. p. 13-32.

FLORES, A.; DAY, C.; VIANA, I. Profissionalismo Docente em transição: as identidades dos professores em tempos de mudança. Um estudo com professores portugueses e ingleses. In: FLORES, M. A.; VIANA, I. C. (Org.). Profissionalismo Docente em Transição: as Identidades dos Professores em tempos de Mudança. Braga: Universidade do Minho, Cadernos CIED, 2007. p. 7-45.

FOUCAULT, M. Vigiar e Punir. Petrópolis, RJ: Vozes, 1997.

GONÇALVES, J. A. Prática Docente e Identidade Profissional. In: ESTRELA, A.; CANÁRIO, R.; FERREIRA, J. (Orgs.). Formação, Saberes Profissionais e Situações de Trabalho. In: COLÓQUIO NACIONAL DA AIPELF/AFIRSE, VI., 1996, Lisboa. Anais... Lisboa: Universidade de Lisboa, 1996. p. 364-377.

HERDEIRO, R. Trabalho Docente e Desenvolvimento Profissional. Narrativas de professores. Lisboa: Chiado Editora, 2010.

HERDEIRO, R. Identidade(s), Carreira e Desenvolvimento Profissional. Um estudo junto de professores do $1^{\circ} \mathrm{CEB}$. Tese (Doutorado) - Universidade do Minho, Instituto de Educação, Braga, 2012.

LEYENS, J. P.; YZERBYT, V. Relações e conflito intergrupos. In: Psicologia social. Lisboa: Edições 70, 1999. p. 263-293.

LIMA, L. C. Políticas Educativas, Novas (e velhas) Oportunidades. In: NEDUM (Org.). A Educação na viragem no Século XX. Atas das I Jornadas de Educação. Braga: Universidade do Minho, 1998. p. 19-27. 
LIMA, L. C. As culturas colaborativas nas escolas. Estruturas, processos e conteúdos. Porto: Porto Editora, 2002.

LIMA, L. C. Administração Escolar: Estudos. Porto: Porto Editora, 2011.

LOPES, A.; PEREIRA, F. Culturas escolares, perspectivas curriculares e identidades profissionais dos professores portugueses. In: LOPES, A. C.; LEITE, C. (Orgs.). Politicas educativas e dinâmicas curriculares em Portugal e no Brasil. Porto: Livpisc, 2008. p. 95-113.

MINISTÉRIO DA EDUCAÇÃO. Relatório nacional sobre a implementação do Programa de Trabalho Educação e Formação 2010. Lisboa: ME, 2005.

PAPADOPOULOS, G. S. Aprender para o século XXI. In: DELORS, J. (Org.). A educação para o século XXI: questões e perspectivas. Porto Alegre: Artmed Editora, 2005. p. 19-34.

PERNIOLA, M. Do sentir. Lisboa: Presença Editora, 1993.

PORTAL DO GOVERNO. Portal do XVII Governo Constitucional. 2005. Disponível em: <http://www.mne.gov.pt/Portal/PT/Governos/Governos.Constitucionais/GC17/ Programa/programa_pooo.htm>. Acesso em: 26 nov. 2011.

ROGERS, C. R. Tornar-se pessoa. Lisboa: Moraes Editores, 1985.

SANCHES, M. Professores, Novo Estatuto e Avaliação de Desempenho. Identidades, visões e instrumentos para a ação. V.N. Gaia: Fundação Manuel Leão, 2008.

SECO, G. A satisfação dos professores. Teorias, modelos e evidências. Porto: Edições Asa, 2002.

SILVA, A. M. Ser professor(a): dinâmicas identitárias e desenvolvimento profissional. In: FLORES, M. A.; VIANA, I. C. (Orgs.). Profissionalismo Docente em Transição: as Identidades dos Professores em tempos de Mudança. Braga: Universidade do Minho, Cadernos CIEd, 2007. p. 155-163.

SIMÕES, G. A avaliação do desempenho docente. Contributos para uma análise crítica. Lisboa: Texto Editora, 2000.

TAVARES, J. Clarificação dos conceitos básicos, objetivos a atingir e suas implicações no processo de ensino/aprendizagem. In: TAVARES, J. (Ed.). Dimensão Pessoal e Interpessoal na Formação. Aveiro: CIDInE, 1993. p. 13-26.

TAVARES, J. Uma sociedade que aprende e se desenvolve. Relações Interpessoais. Porto: Porto Editora, 1996.

TEIXEIRA, M. Os professores face à profissão: gosto ou desgosto? In: TEIXEIRA, M. (Org.). Ser professor no Limiar do Século XXI. Porto: Edições ISET, 2001. p. 183-265.

TEODORO, A. Professores, para quê? Mudanças e Desafios na Profissão Docente. Porto: Profedições, 2006. 


\section{LEGISLAÇÃO CONSULTADA}

PORTUGAL. Decreto-Lei no 240/2001, de 30 de agosto de 2001. Perfil de Desempenho Profissional. Diário da República - 1. ${ }^{\mathrm{a}}$ Série-A - n. ${ }^{\circ} 201-30$ de Agosto de 2001, p. 5572-5575. Disponível em: <http://neebuminho.weebly.com/uploads/1/1/3/4/11346831/ decreto_lei_241.2001.pdf >.Acesso em: 01 jul. 2015.

PORTUGAL. Decreto-Lei $n^{\circ}$ 15/2007, de 19 de janeiro de 2007. Estatuto da Carreira Docente. Disponível em: <http://www.centrobsb.com/files/Legis/pd/Decreto-Lei_n_15-2007.pdf>. Acesso em: 01 jul. 2015.

PORTUGAL. Decreto Regulamentar nº 2/2008, de 10 de janeiro de 2008. Avaliação do Desempenho Docente. Diário da República, 1. a série - n. ${ }^{\circ} 7$ - 10 de Janeiro de 2008, p. 226-233. Disponível em: <http://www.ige.min-edu.pt/upload/GTAA/DR_2_2008.pdf >. Acesso em: 01 jul. 2015.

PORTUGAL. Estratégia de Lisboa - Rede de Coordenação Nacional da Estratégia de Lisboa e do Plano Tecnológico. Conselho Europeu em Lisboa em Março de 2000. Disponível em: $<$ http://www.dges.mctes.pt/DGES/pt/Reconhecimento/Uni\%C3\%A3o+Europeia/ Estrat\%C3\%A9gia+Europa+2020/Estrategia+Lisboa.htm>. Acesso em: 01 jul. 2015.

Texto recebido em 25 de maio de 2015. Texto aprovado em 10 de junho de 2015. 